University of Nebraska - Lincoln

DigitalCommons@University of Nebraska - Lincoln

Agronomy \& Horticulture -- Faculty Publications

Agronomy and Horticulture Department

2009

\title{
Non-Destructive Determination of Maize Leaf and Canopy Chlorophyll Content
}

\author{
Veronica Ciganda \\ University of Nebraska-Lincoln
}

Anatoly A. Gitelson

University of Nebraska-Lincoln, agitelson2@unl.edu

James S. Schepers

University of Nebraska-Lincoln, james.schepers@gmail.com

Follow this and additional works at: https://digitalcommons.unl.edu/agronomyfacpub

Part of the Plant Sciences Commons

Ciganda, Veronica; Gitelson, Anatoly A.; and Schepers, James S., "Non-Destructive Determination of Maize Leaf and Canopy Chlorophyll Content" (2009). Agronomy \& Horticulture -- Faculty Publications. 170.

https://digitalcommons.unl.edu/agronomyfacpub/170

This Article is brought to you for free and open access by the Agronomy and Horticulture Department at DigitalCommons@University of Nebraska - Lincoln. It has been accepted for inclusion in Agronomy \& Horticulture -Faculty Publications by an authorized administrator of DigitalCommons@University of Nebraska - Lincoln. 
Available online at www.sciencedirect.com $\because$ ScienceDirect
JOURNAL OF
PLANT PHYSIOLOGY

www.elsevier.de/jplph

\title{
Non-destructive determination of maize leaf and canopy chlorophyll content
}

\author{
Verónica Ciganda ${ }^{a, b}$, Anatoly Gitelson $^{a, *}$, James Schepers ${ }^{c}$
}

\author{
${ }^{a}$ Center for Advanced Land Management Information Technology (CALMIT), School of Natural Resources, \\ University of Nebraska-Lincoln, 303 Hardin Hall, 3310 Holdrege, Lincoln, NE 68583-0973, USA \\ bINIA La Estanzuela, CC 39173 Colonia, Uruguay \\ 'USDA-ARS and Department of Agronomy and Horticulture, University of Nebraska-Lincoln, Lincoln, NE, USA
}

Received 19 February 2008; received in revised form 28 March 2008; accepted 31 March 2008

KEYWORDS

Chlorophyll;

Maize;

Model;

Non-destructive;

Reflectance

\begin{abstract}
Summary
The objective of this study was to develop a rapid non-destructive technique to estimate total chlorophyll ( $\mathrm{Chl}$ ) content in a maize canopy using Chl content in a single leaf. The approach was (1) to calibrate and validate a reflectance-based nondestructive technique to estimate leaf $\mathrm{Chl}$ in maize; (2) to quantify the relative contribution of each leaf $\mathrm{Chl}$ to the total $\mathrm{Chl}$ in the canopy; and (3) to establish a relationship between leaf $\mathrm{Chl}$ content and total $\mathrm{Chl}$ in a maize canopy. The Red Edge Chlorophyll Index $\mathrm{Cl}_{\text {red edge }}=\left(R_{\mathrm{NIR}} / R_{\text {red edge }}\right)-1$ based on reflectances, $R$, in the red edge $(720-730 \mathrm{~nm})$ and near infrared $(770-800 \mathrm{~nm})$ was found to be an accurate measure of maize leaf $\mathrm{Chl}$. It was able to predict leaf $\mathrm{Chl}$ ranging from 10 to $805 \mathrm{mg} \mathrm{Chl} \mathrm{m}^{-2}$ with root mean-square error less than $38 \mathrm{mg} \mathrm{Chl} \mathrm{m}^{-2}$. Relationships between $\mathrm{Chl}$ content in each maize leaf and total canopy $\mathrm{Chl}$ content were established and showed that $\mathrm{Chl}$ in the collar leaf before silking or ear leaves explained more than $80 \%$ and $87 \%$ of the variation in total Chl in a maize canopy, respectively. Thus, non-destructive measurements of both reflectance and area of a single leaf (either collar or ear) can be used to accurately estimate total Chl content in a maize canopy.
\end{abstract}

\section{Introduction}

Abbreviations: Chl, chlorophyll; $\mathrm{Cl}$, chlorophyll index; RMSE, root mean-squared error.

*Corresponding author. Tel.: +1 4024728386 ;

fax: +14024722946 .

E-mail address: agitelson2@unl.edu (A. Gitelson).
The production of dry matter by pasture and crop species has been demonstrated to be ultimately limited by the amount of chlorophyll (Chl) due to the strong relationship of this pigment with the 
photosynthetic processes (Sprague and Curtis, 1933; Brougham, 1960; Lieth and Whittaker, 1975; Dawson et al., 2003). Irrespective of the efficiency with which the various tissues and organs of the plant may function, a deficient supply of $\mathrm{Chl}$ or its inefficient operation limits plant growth (Sprague and Curtis, 1933). In turn, canopy biophysical parameters such as $\mathrm{N}$ content (Evans, 1989), above-ground biomass, green leaf area index, net ecosystem $\mathrm{CO}_{2}$ exchange (Lieth and Whittaker, 1975; Gitelson et al., 2006a), absorbed photosynthetic active radiation (Viña and Gitelson, 2005), and yield (Walters, 2003) have been related to canopy Chl content. Chl content has been suggested as the community property most directly relevant to the prediction of productivity (Lieth and Whittaker, 1975; Dawson et al., 2003). Foyer et al. (1982) further affirmed that "... all quantitative means for expressing photosynthetic rate in current use (for example, ground area, fresh weight) carry inescapable disadvantages. Chl is likely to remain the universal basis for expressing photosynthetic rate."

Destructive techniques have been traditionally used for the determination of $\mathrm{Chl}$ content in vegetation stands. In general, they involve very laborious and destructive sampling plus various analytical protocols (e.g., Brougham, 1960; Lieth and Whittaker, 1975; Tucker, 1977). These techniques implicitly assume (1) a homogeneous contribution of $\mathrm{Chl}$ from the different canopy components, (2) a linear and consistent relationship between $\mathrm{Chl}$ content in the sample and total $\mathrm{Chl}$ in the canopy, or (3) both. However, current knowledge does not provide quantitative and precise descriptions of the distribution of $\mathrm{Chl}$ in a canopy for different vegetation stands. In addition, there are no reported relationships either among or between different canopy components and total $\mathrm{Chl}$ content of a canopy. On the contrary, it is well known that the distribution of $\mathrm{Chl}$ among leaves ultimately depends on the canopy acclimation to light penetration (e.g., Kull, 2002), characteristics of each canopy species, and the environment. Further, the distribution of Chl within a canopy can vary considerably as a function of time and space, making the estimation of canopy Chl content through destructive sampling a labor-intensive and expensive process (e.g., Coops et al., 2003).

The distribution of $\mathrm{Chl}$ within maize leaves is, in general, quite homogeneous at a specific growth stage. However, either biotic or abiotic factors can induce stress in a plant affecting specific processes on individual leaves resulting in both a loss of $\mathrm{Chl}$ and a change in its distribution pattern (Barton, 2000). Consequently, methods are required for accurate, non-destructive, and simple estimates of $\mathrm{Chl}$ content at canopy scales, rather than for individual leaves (Curran et al., 1990). These methods should improve the accuracy of $\mathrm{Chl}$ estimation by taking into account the variability in $\mathrm{Chl}$ content within and among leaves in the canopy.

The use of portable Chl meters (e.g., Minolta SPAD) has been proposed as a non-destructive technique to estimate $\mathrm{Chl}$ content by means of absorbance/transmittance measurements (e.g., Piekielek and Fox, 1992; Markwell et al., 1995). Richardson et al. (2002) evaluated the performance of optical methods that are based on the absorbance/transmittance and reflectance of certain wavelengths of light by intact leaves. They concluded that non-invasive optical methods all provided reliable estimates of leaf $\mathrm{Chl}$. However, some reflectance indices (Gitelson and Merzlyak, 1994) consistently out-performed two commercially available hand-held $\mathrm{Chl}$ absorbance meters CCM-200 and the SPAD-502. Steele et al. (2008) further showed that the SPAD-502 has adequate sensitivity to $\mathrm{Chl}$ content below $300 \mathrm{mg} \mathrm{m}^{-2}$. Above that level, however, the accuracy of the instrument considerably diminished. This decrease in sensitivity takes place in the range of $\mathrm{Chl}$ that is typical for green vegetation, which prevents using SPAD for accurate measurement of $\mathrm{Chl}$ in healthy vegetation and indication of early (pre-visual) stages of plant stress.

Non-destructive techniques based on leaf reflectance have been proposed as alternative, robust, and simple methods for pigment quantification in leaves (Collins, 1978; Curran and Milton, 1983; Buschmann and Nagel, 1993; Gitelson and Merzlyak, 1994, 1996; Richardson et al., 2002; Sims and Gamon, 2002; Gitelson et al., 2003; Hu et al., 2004; Le Maire et al., 2004) and in canopies (e.g., Barton, 2000; Gitelson et al., 2005). However, an important uncertainty remains when $\mathrm{Chl}$ content values for individual leaves are used to represent the $\mathrm{Chl}$ content in the canopy. Gitelson et al. (2005) estimated total $\mathrm{Chl}$ in maize canopies during the growing season as $\mathrm{Chl}=\mathrm{Chl}_{\text {upper }} \times$ green LAl, where $\mathrm{Chl}_{\text {upper }}$ is the Chl content of the upper leaf and green LAl is the green leaf area index of the canopy. This approach markedly improved current techniques proposed for Chl quantification in the canopy. However, the major assumption of this approach Chl content of the uppermost expanded leaf represents the $\mathrm{Chl}$ content of the plant - was not proved in the cited paper.

There is still a lack of accurate, rapid, and practical methodologies available to quantify $\mathrm{Chl}$ content in the canopy per unit of ground area. 
The general objective of this study is to find a way to accurately and quantitatively characterize canopy $\mathrm{Chl}$ content using $\mathrm{Chl}$ content in a single leaf. Specific objectives were (1) to calibrate and validate a reflectance-based non-destructive technique (Gitelson and Merzlyak, 1994; Gitelson et al., 2003, 2006b) to estimate leaf $\mathrm{Chl}$ in maize; (2) to quantify the relative contribution of each leaf $\mathrm{Chl}$ to the total Chl in the canopy; and (3) to establish a relationship between leaf $\mathrm{Chl}$ content and total $\mathrm{Chl}$ in a maize canopy.

\section{Materials and methods}

This study took advantage of an established research facility, which is part of the Carbon Sequestration Program at the University of Nebraska-Lincoln. The research facility consists of three agricultural fields of approximately 65 ha each, located in the vicinity of Lat. $41.175 \mathrm{~N}$, Long. $96.425 \mathrm{~W}$. The cropping system was established in 2001 and differs among the three fields: field 1 is under continuous sprinkler-irrigated maize; field 2 is a sprinkler-irrigated maize-soybean rotation; and field 3 is a rain-fed maize-soybean rotation. The study took place in the 2004 and 2005 growing seasons. In 2004, field 1 was planted with maize hybrid Pioneer brand 33B51. In 2005, fields 1 and 2 were planted with maize hybrids Dekalb 6375 (D-6375) and Pioneer brand 33B51 (P-33B51), respectively, and field 3 was planted with maize hybrid Pioneer brand 31G68 (P-31G68).

\section{Sampling and labeling procedures}

Three plants from each field were sampled weekly or biweekly during the reproductive period after tasseling of the 2004 growing season and during the entire 2005 growing season: from the early vegetative growth stage beginning with the third leaf developed through late reproductive stages.

A total of 26 plants in 2004 and 128 in 2005 were sampled resulting in approximately 300 and 2000 leaves measured in the first and second years, respectively. Once the plants were selected, the position of the collar or ear leaf was identified. The collar leaf was defined as the uppermost leaf whose leaf collar is visible (Ritchie et al., 1992), while the ear leaf was defined as the leaf next to the maize ear. Positions of the other leaves on each plant were numerically labeled with respect to the collar or the ear leaf position during vegetative or reproductive stages, respectively. The position of the collar or ear leaf was labeled as leaf position 0 . The leaves above or below leaf 0 , were identified with a " ", or a "-" sign, respectively, followed by the corresponding position number. For example, the first leaf above the ear/collar leaf was identified as +1 , the second one as +2 , the third one +3 , etc., up to the top leaf. In contrast, the first leaf below the ear/collar leaf was identified as -1 , the second as -2 , the third one as -3 until the closest leaf to the ground was reached. After labeling, the leaves were cut from the stem, placed in a sealed plastic bag, and brought to the laboratory inside a cooler.

\section{Non-destructive estimation of leaf chlorophyll content}

Leaf Chl content was measured using a recently developed technique based on models that relate leaf reflectance with pigment content (Gitelson et al., 2003). One of the models, so-called Red Edge Chlorophyll Index,

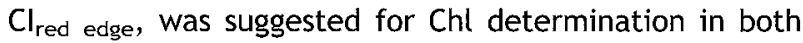
anthocyanin-containing and anthocyanin-free leaves (Gitelson et al., 2006b). $\mathrm{Cl}_{\text {red }}$ edge was tested in this study; it is based on reflectances in the red edge ( $\left.R_{\text {red edge }}\right)$ and near infrared $\left(R_{\mathrm{NIR}}\right)$ wavebands and defined as:

$\mathrm{Cl}_{\text {red edge }}=\left(R_{\mathrm{NIR}} / R_{\text {red edge }}\right)-1$

where $R_{\text {NIR }}$ is average reflectance in the range from 770 to $800 \mathrm{~nm}$ and $R_{\text {red edge }}$ is the average reflectance in the range from 720 to $730 \mathrm{~nm}$.

Once during the growing season, maize leaves within a wide range of greenness were collected from the crop fields in 2004 (20 leaves) and 2005 (61 leaves). Reflectance of each leaf was measured in the spectral range from 400 to $900 \mathrm{~nm}$ using a leaf clip, with a 2.3$\mathrm{mm}$-diameter bifurcated fiber-optic cable attached to both an Ocean Optics USB2000 spectroradiometer and to an Ocean Optics LS-1 tungsten halogen light source. The leaf clip allows individual leaves to be held with a $60^{\circ}$ angle relative to the bifurcated fiber-optic. The software CDAP (CALMIT, University of Nebraska-Lincoln Data Management Program) was used to acquire and process the data from the sensor. A Spectralon reflectance standard (99\% reflectance) was scanned before each leaf measurement. The reflectance at each wavelength was calculated as the ratio of upwelling leaf radiance to the upwelling radiance of the standard. The average reflectance obtained from 10 scans was used to compute the

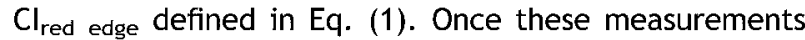
were completed, two to four circular disks $(1 \mathrm{~cm}$ diameter) were punched from each leaf for analytical extraction of $\mathrm{Chl}$ and quantification using absorption spectroscopy. The extraction of Chl was done using $10 \mathrm{~mL}$ of $80 \%$ acetone. The extinction absorption coefficients published by Porra et al. (1989) were used for final calculations of total Chl content.

For establishing a relationship between chlorophyll index $\mathrm{Cl}_{\text {red edge }}$ and $\mathrm{Chl}$ content, the dataset collected in 2005 was used. A linear relationship between $\mathrm{Cl}_{\text {red edge }}$ and $\mathrm{Chl}$ was established in the form

$\mathrm{Chl}\left(\mathrm{mg} \mathrm{m}^{-2}\right)=a \times \mathrm{Cl}_{\text {red edge }}+b$

Validation of the technique was performed on an independent dataset of 20 leaves collected in 2004. Reflectance and $\mathrm{Chl}$ content $\left(\mathrm{Chl}_{\text {meas }}\right)$ of these leaves were measured using the procedures described above. Calibration Eq. (2) was used to predict Chl in leaves $\left(\mathrm{Chl}_{\text {pred }}\right)$ of this dataset. The accuracy of $\mathrm{Chl}$ prediction was quantified by root mean-square error (RMSE) of $\mathrm{Chl}_{\text {pred. }}$. 


\section{Estimation of chlorophyll content in canopy}

In the laboratory, each leaf of the canopy was visually examined to identify and separate sections that were different in color. Leaf sections were marked, labeled, and cut for further measurements. Ten reflectance scans were recorded from each leaf or leaf section with different colors. In the case of a leaf that was considered homogeneous in color, ten randomly distributed scans were made along the leaf margin (both sides of midrib). However, in the case of a leaf with a heterogeneous distribution of color, sections that appeared homogeneous in color were treated independently and ten randomly distributed scans were taken on each such leaf section.

The mean of the reflectance obtained from each set of ten scans was used to compute the $\mathrm{Cl}_{\text {red edge }}$ defined in Eq. (1). Then, Chl content (in $\mathrm{mg} \mathrm{m}^{-2}$ ) of each leaf $\left(\mathrm{Chl}_{\text {leaf }}\right)$ or leaf section $\left(\mathrm{Chl}_{\text {sect }}\right)$ was estimated using Eq. (2).

Once the reflectance measurements were completed, the area of each leaf, $S_{\text {leaf }}$, or the area of each leaf section, $S_{\text {sect }}$ (in the case of heterogeneous leaves) was measured with a leaf area meter (Model LI-3100A, Li-Cor, Inc., Lincoln, NE). Total weight of $\mathrm{Chl}_{\text {wt/leaf }}$ (in $\mathrm{g}$ ) in individual leaves was calculated as a product of leaf area $\mathrm{S}_{\text {leaf }}\left(\right.$ in $\left.\mathrm{m}^{2}\right)$ and its $\mathrm{Chl}$ content $\left(\mathrm{Chl}_{\text {leaf }}\right.$ in $\left.\mathrm{mg} \mathrm{m}^{-2}\right)$. In the case of leaves with " $m$ " sections (i.e., with " $m$ " areas of different "greenness"), the sum of the products of each section area (in $\mathrm{m}^{2}$ ) and each section $\mathrm{Chl}$ content $\left(\mathrm{Chl}_{\text {sect }}\right.$, in $\mathrm{g} \mathrm{m}^{-2}$ ) resulted in the amount of $\mathrm{Chl}$ of the entire leaf $\left(\mathrm{Chl}_{\mathrm{wt} / \text { leaf }}\right)$. This was calculated using following equation:

$\mathrm{Chl}_{\text {wt/leaf }}(\mathrm{g})=\sum_{i=1}^{m} \mathrm{Chl}_{\text {sect }}^{i} \times S_{\text {sect }}^{i}$
Total amount of $\mathrm{Chl}$ in the canopy ( $\left.\mathrm{Chl}_{\text {canopy }}\right)$, expressed as the amount of Chl per unit of ground area (i.e., $\mathrm{g} \mathrm{Chl} \mathrm{m}^{-2}$ ground), was calculated as the sum of $\mathrm{Chl}$ of individual leaves $\left(\mathrm{Chl}_{\mathrm{wt} / \text { leaf }}\right)$ of each plant normalized to ground area, $S_{\text {ground }}$ :

$$
\mathrm{Chl}_{\text {canopy }}=\sum_{i=1}^{n}\left(\mathrm{Chl}_{\mathrm{wt} / \text { leaf }}\right)_{i} / \mathrm{S}_{\mathrm{ground}}
$$

where $n$ is number of leaves in each plant, $\mathrm{Chl}_{\text {wt/leaf }}$ is chlorophyll (in g) of each leaf, calculated from Eq. (3), and $S_{\text {ground }}$ (in $\mathrm{m}^{2}$ ) was calculated as a product of the average distance between plants in the row and the distance between rows. The relationship between leaf $\mathrm{Chl}$ and canopy $\mathrm{Chl}$ defined in Eq. (4) was established using data collected in $2005(n=128)$ and validated with an independent dataset collected in $2004(n=26)$.

\section{Results and discussion}

\section{Non-destructive leaf $\mathrm{Chl}$ estimation}

Chl content determined analytically in the dataset consisting of 61 maize leaves acquired in 2005 varied widely from 22 to $886 \mathrm{mg} \mathrm{Chl} \mathrm{m}^{-2}$. The relationship between analytical $\mathrm{Chl}$ and the reflectance-based $\mathrm{Cl}_{\text {red edge obtained for these leaves was }}$ described by a linear best-fit function with a coefficient of determination of $r^{2}>0.94$ and RMSE of less than $51 \mathrm{mg} \mathrm{Chl} \mathrm{m}^{-2}$ (Figure 1):

Chl $\left(\mathrm{mg} \mathrm{m}^{-2}\right)=37.904+1353.7 \times \mathrm{Cl}_{\text {red edge }}$

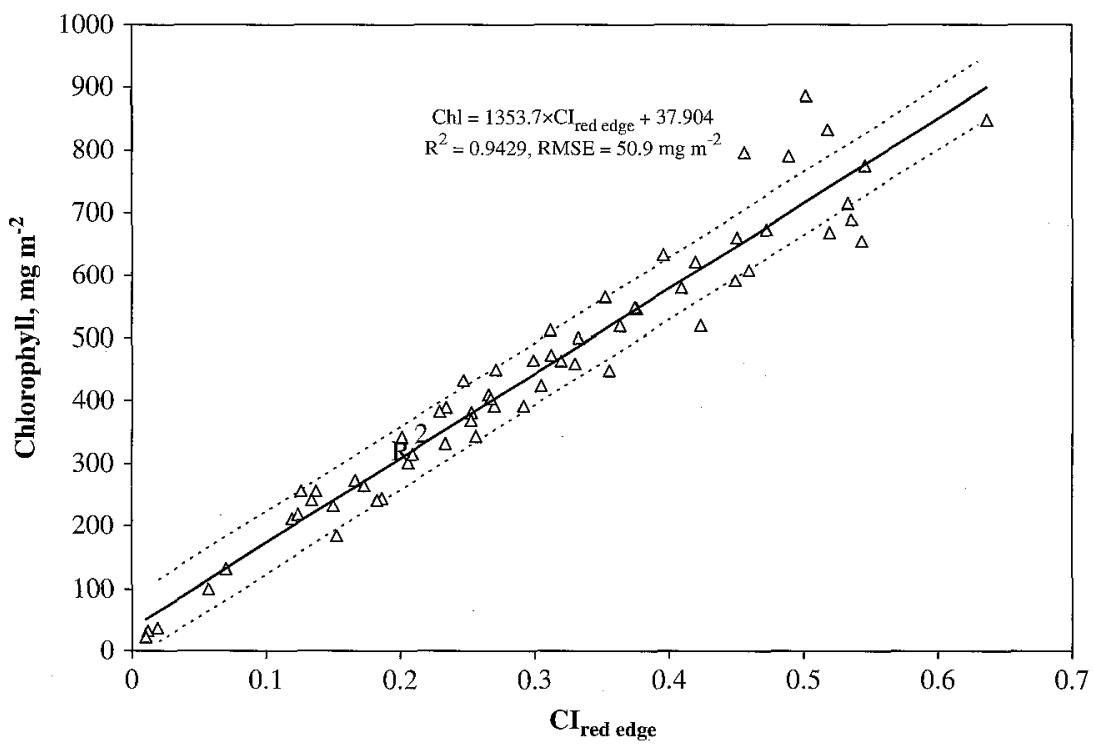

Figure 1. Relationship between Chl content in leaves and Red Edge Chlorophyll Index $\mathrm{Cl}_{\text {red edge }}=\left(R_{\mathrm{NIR}} / R_{\text {red edge }}\right)-1$ for the 2005 dataset. This relationship was used for calibration of the non-destructive determination of Chl from leaf reflectance. Solid line is the best-fit function; dotted lines correspond to one standard error of chlorophyll estimation. RMSE is root mean-square error of leaf Chl estimation. 
The algorithm (Eq. (5)) was validated by an independent dataset of 20 maize leaves taken in 2004. Predicted $\mathrm{Chl}$ content $\left(\mathrm{Chl}_{\text {pred }}\right)$ was closely linearly related to $\mathrm{Chl}$ content measured analytically ( $\mathrm{Chl}_{\text {meas }}$ ) with RMSE $<38 \mathrm{mgChl} \mathrm{m}^{-2}$ and coefficient of variation (CV) less than $10.3 \%$ (Figure 2):

$\mathrm{Chl}_{\text {pred }}=16.53+0.89 \times \mathrm{Chl}_{\text {meas }}$

\section{Total Chl in canopy and its relation to leaf $\mathrm{Chl}$}

Total $\mathrm{Chl}$ in canopy increased during the vegetative growth period, reaching a maximum close to tasseling (VT) and then decreased during reproductive and senescence periods (Figure 3). Hybrid P-31G68, grown under rain-fed conditions showed lower values of total $\mathrm{Chl}$ content through the entire growing season. However, the three hybrids followed the same pattern of $\mathrm{Chl}$ changes over time.

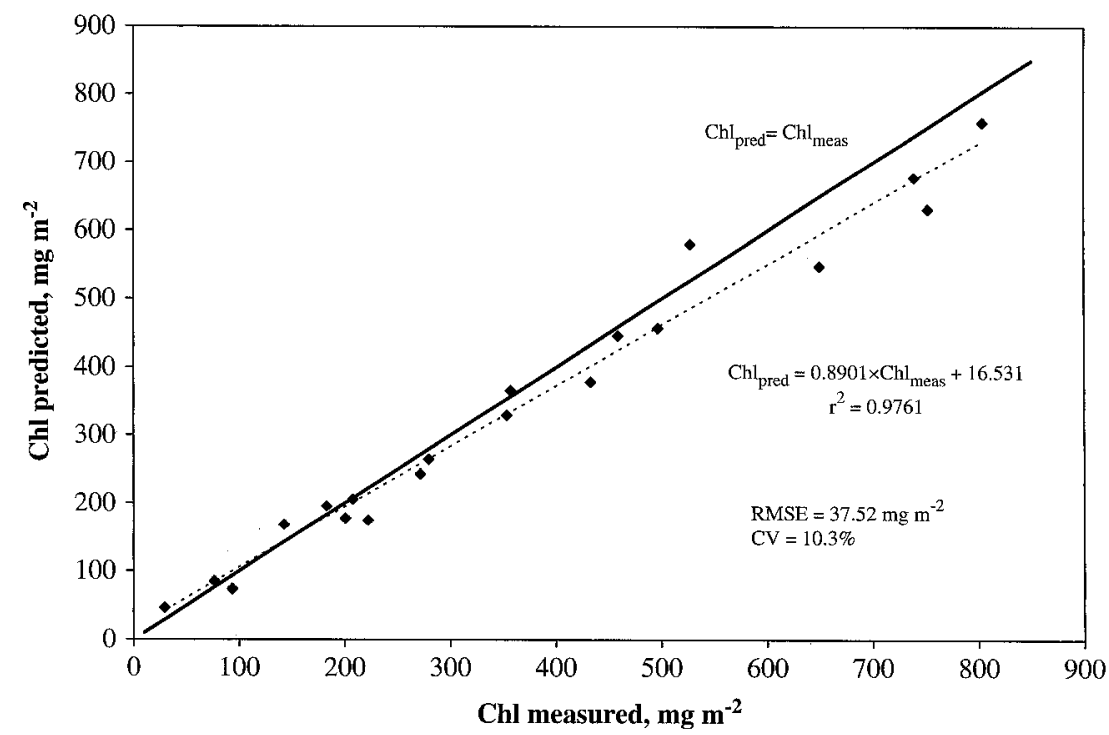

Figure 2. Chlorophyll predicted by the Red Edge Chlorophyll Index plotted vs. measured analytically. Solid line is $\mathrm{Chl}_{\text {pred }}=\mathrm{Chl}_{\text {meas; }}$; dotted line is best-fit function $\mathrm{Chl}_{\text {pred }} \mathrm{vs}$. Chl $\mathrm{Cheas}_{\text {. }} \mathrm{RMSE}$ is root mean-square error of leaf $\mathrm{Chl}$ prediction.

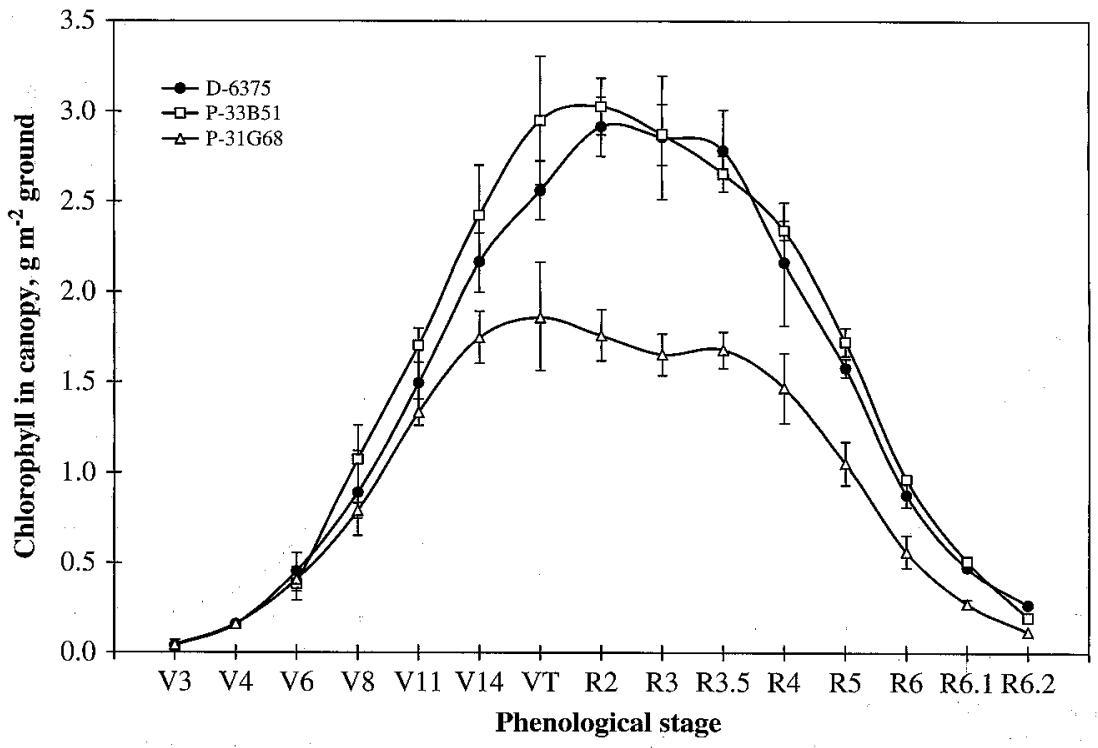

Figure 3. Total chlorophyll content in canopy (per ground area) of three maize hybrids during the growing season. Each point represents the average chlorophyll content in three plants and the vertical bars represent the standard error. 


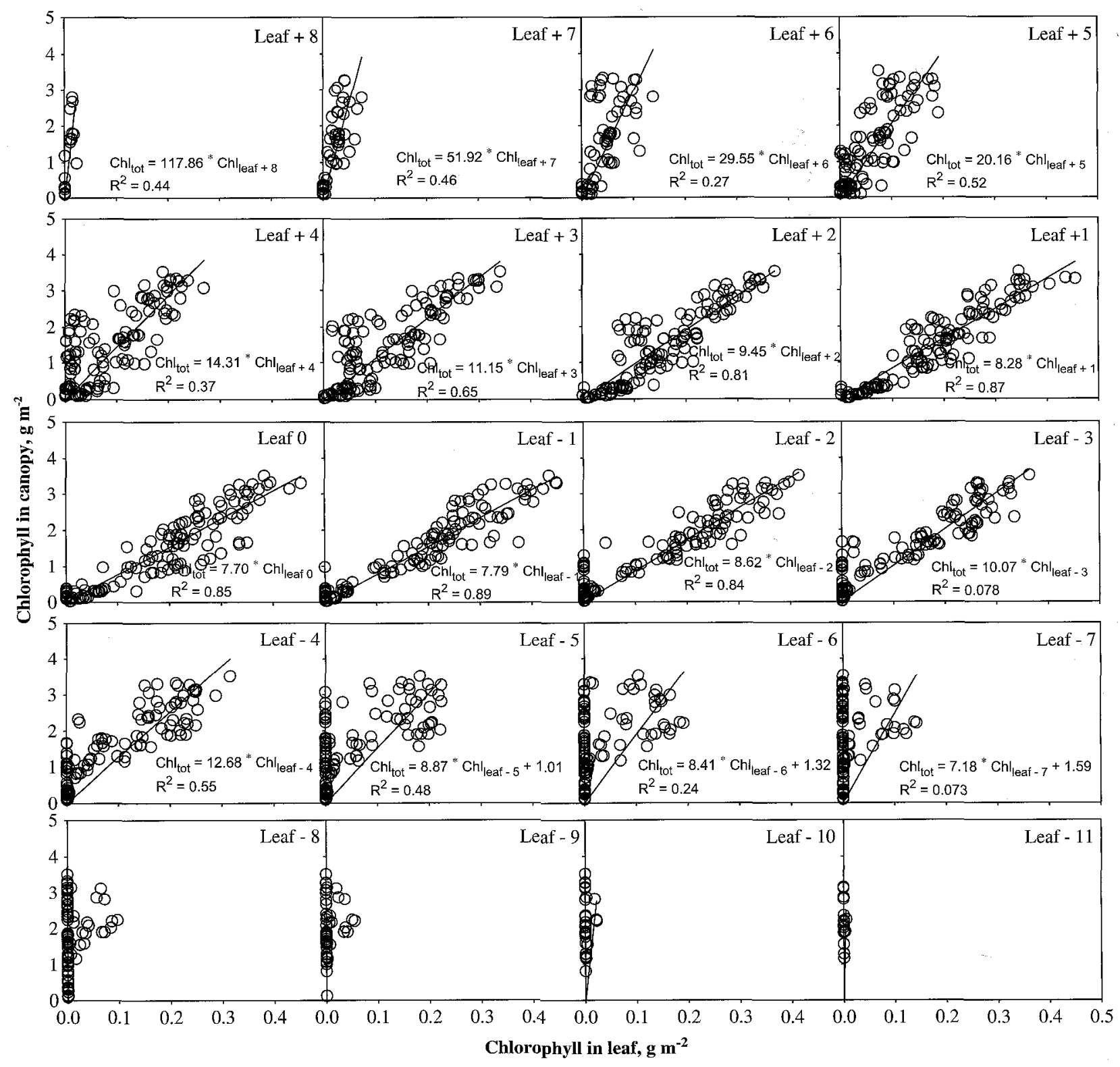

Figure 4. Relationships between chlorophyll content in canopy and chlorophyll content in individual leaves (both calculated per ground area). Data from three hybrids (D-6375, P-31G68, and P-33B51) are pooled together. Leaf in position 0,0 leaf, corresponds to the collar or ear leaf during vegetative and reproductive periods, respectively. Positive and negative numbered leaves correspond to leaves positioned above or below 0 leaf, respectively.

The relationships between $\mathrm{Chl}$ content in individual leaves ( $\mathrm{Chl}_{\text {leaf }}$ ) located at different plant positions and total $\mathrm{Chl}$ content in the canopy $\left(\mathrm{Chl}_{\text {canopy }}\right)$ are shown in Figure 4. Leaf in position 0 corresponds to the collar or ear leaf during vegetative and reproductive periods, respectively. Positive and negative numbered leaves correspond to leaves positioned above or below 0 , respectively, The parameters of the linear relationships between $\mathrm{Chl}_{\text {leaf }}$ and $\mathrm{Chl}_{\text {canopy }}$ varied with the position of the leaf. From the top to the middle leaf positions, down to leaf position -1 the slope of these relationships decreased while the coefficient of determination $\left(r^{2}\right)$ increased from 0.44 to 0.89 . $\mathrm{Chl}_{\text {leaf }}$ also increased from top to middle positioned leaves. From middle to bottom positioned leaves the relation $\mathrm{Chl}_{\text {leaf }}$ vs. $\mathrm{Chl}_{\text {canopy }}$ becomes weaker, showing a higher dispersion of the points and lower $r^{2}$.

The highest correlation between $\mathrm{Chl}_{\text {leaf }}$ and $\mathrm{Chl}_{\text {canopy }}$ was found among $+1,0$, and -1 leaves with $r^{2}$ of $0.87,0.85$, and 0.89 , respectively. The relationships $\mathrm{Chl}_{\text {leaf }}$ vs. $\mathrm{Chl}_{\text {canopy }}$ were weaker for both above and below +1 and -1 leaves. It is important to note that for leaves positioned below -4 the relationship was markedly weaker. This 
phenomenon was so intense for the last four leaf positions, -8 through -11 , that it was not possible to fit a model (bottom row in Figure 4).

The relationship between $\mathrm{Chl}_{\text {leaf }}$ and $\mathrm{Chl}_{\text {canopy }}$ is governed by both the leaf $\mathrm{Chl}$ content and the leaf area (Figure 5). The $r^{2}$ of these relationships followed a bell shape distribution: highest $r^{2}$ values were for leaves in the middle of canopy and gradually decreased to both top and bottom leaves (Figure 5). Chl leaf $_{\text {le }}$ the upper leaves, +8 and +7 , could explain only about $45 \%$ of the variability of total $\mathrm{Chl}_{\text {canopy. }}$ On the other hand, $\mathrm{Chl}_{\text {leaf }}$ of the leaves positioned in the middle of the canopy, -1 , 0 , and +1 , were closely related to $\mathrm{Chl}_{\text {canopy }}$ and each of them could explain more than $85 \%$ of the variability in $\mathrm{Chl}_{\text {canopy. }}$.

\section{Estimation of canopy Chl from a single leaf Chl}

The Chl content of three single leaves, $0,+1$, or -1 , was found to be the best proxy of $\mathrm{Chl}_{\text {canopy }}$ (Figures 4 and 5). Each leaf could explain more than $85 \%$ of the total canopy $\mathrm{Chl}$ variability. In practical terms, however, 0 leaf is the easiest leaf to identify in the plant under field conditions and its contribution to $\mathrm{Chl}_{\text {canopy }}$ was one of the highest during the growing season. Thus, the relationship of $\mathrm{Chl}$ in 0 leaf vs. $\mathrm{Chl}_{\text {canopy }}$ was analyzed in detail to develop a simple technique for the estimation of $\mathrm{Chl}_{\text {canopy }}$. Note that 0 leaf represents the collar leaf during the vegetative period and the ear leaf in the reproductive period. Therefore, the relationship

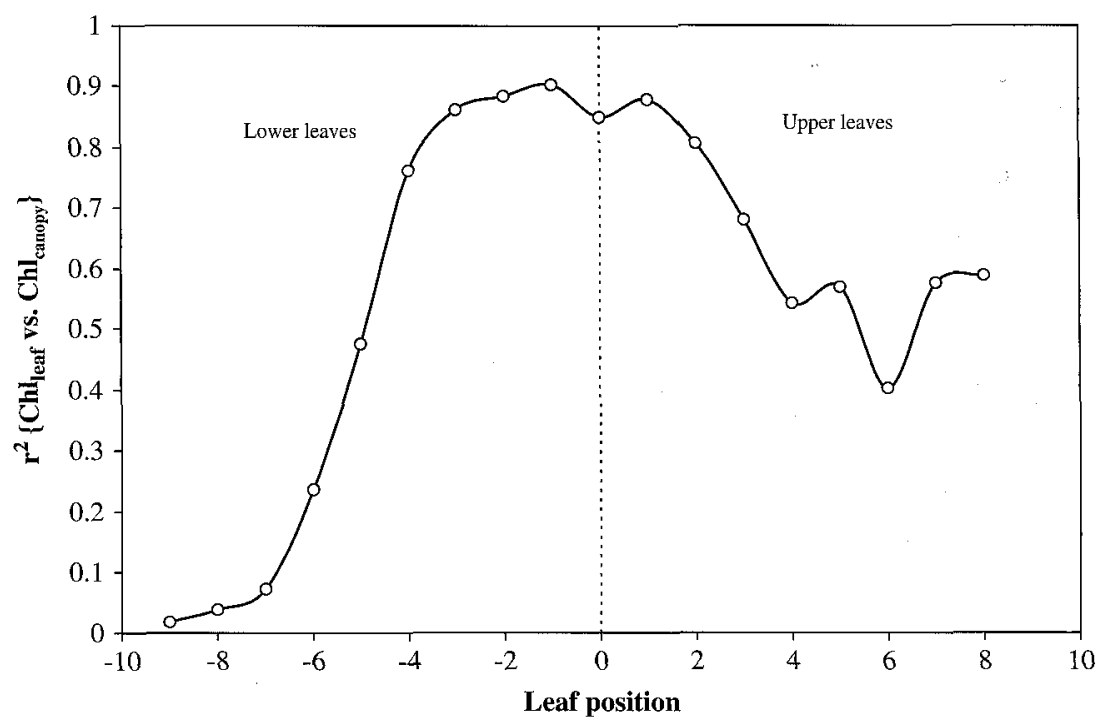

Figure 5. The coefficient of determination, $r^{2}$, of the linear relationship $\mathrm{Chl}_{\text {canopy }}$ vs. Chl leaf plotted vs. leaf position. Leaf 0 corresponds to the collar or ear leaf during vegetative and reproductive periods, respectively. Positive and negative numbered leaves correspond to leaves positioned above or below 0 leaf, respectively.

Table 1. Intercept, slope, RMSE, and coefficient of determination $\left(r^{2}\right)$ of the linear relationship between chlorophyll content in the collar or ear leaf and chlorophyll content in canopy, Chl canopy vs. Chl leaf, for three hybrids: D-6375, P33B51, and P-31G68, and all samples together

\begin{tabular}{lllllll}
\hline Leaf & Hybrid & $n$ & $r^{2}$ & intercept $\left(\mathrm{gChlm}^{-2}\right)$ & Slope & RMSE $\left(\mathrm{gChlm}^{-2}\right)$ \\
\hline Collar & D-6375 & 18 & 0.813 & $-0.076 \mathrm{a}$ & $7.712 \mathrm{~b}$ & 0.350 \\
& P-33B51 & 12 & 0.731 & $-0.148 \mathrm{a}$ & $6.484 \mathrm{~b}$ & 0.399 \\
& P-31G68 & 18 & 0.835 & $-0.125 \mathrm{a}$ & $7.875 \mathrm{~b}$ & 0.294 \\
& Altogether & 48 & 0.795 & 0.000 & 6.562 & 0.352 \\
Ear & D-6375 & 27 & 0.935 & $0.129 \mathrm{c}$ & $8.689 \mathrm{~d}$ & 0.297 \\
& P-33B51 & 27 & 0.851 & $0.024 \mathrm{c}$ & $7.353 \mathrm{~d}$ & 0.465 \\
& P-31G68 & 26 & 0.934 & $0.095 \mathrm{c}$ & $7.858 \mathrm{~d}$ & 0.183 \\
& Altogether & 80 & 0.875 & 0.000 & 8.120 & 0.375 \\
\hline
\end{tabular}

$n$ is number of samples. Numbers followed by the same letter are not significantly different at $\alpha=0.001$. Both Chl $_{\text {canopy }}$ vs. Chl leaf were calculated per ground area. 
$\mathrm{Chl}_{\text {leaf }}$ with $\mathrm{Chl}_{\text {canopy }}$ was analyzed within the two growth periods: vegetative and reproductive. In addition, the possible differences among the three hybrids (D-6375, P-33B51, and P-31G68) grown under different cropping systems were taken into account by fitting a linear model for each of them within each growth period (Table 1).

No significant differences were found among hybrids during the vegetative growth period: the slopes and intercepts of the three linear regressions of $\mathrm{Chl}$ content in the collar leaf $\mathrm{Chl}_{\text {collar }}$ vs. $\mathrm{Chl}_{\text {canopy }}$ were not statistically different. Also, during the reproductive period no significant differences were found for the linear relationship $\mathrm{Chl}_{\text {ear }}$ vs. $\mathrm{Chl}_{\text {canopy }}$ among the three hybrids (Table 1 ). These results revealed that the relationships $\mathrm{Chl}_{\text {collar }}$ vs. $\mathrm{Chl}_{\text {canopy }}$ and $\mathrm{Chl}_{\text {ear }}$ vs. $\mathrm{Chl}_{\text {canopy }}$ are consistent and can be used for $\mathrm{Chl}_{\text {canopy }}$ retrieval regardless of hybrid, cropping system, and plant density.

Relationships $\mathrm{Chl}_{\text {collar }}$ vs. $\mathrm{Chl}_{\text {canopy }}$ and $\mathrm{Chl}_{\text {ear }}$ vs. Chl canopy were linear across hybrids (Table 1, Figure 6). Thus, two algorithms for Chl canopy estimation were proposed:

Vegetative period:

$\mathrm{Chl}_{\text {canopy }}=6.56 \times \mathrm{Chl}_{\text {collar }}$
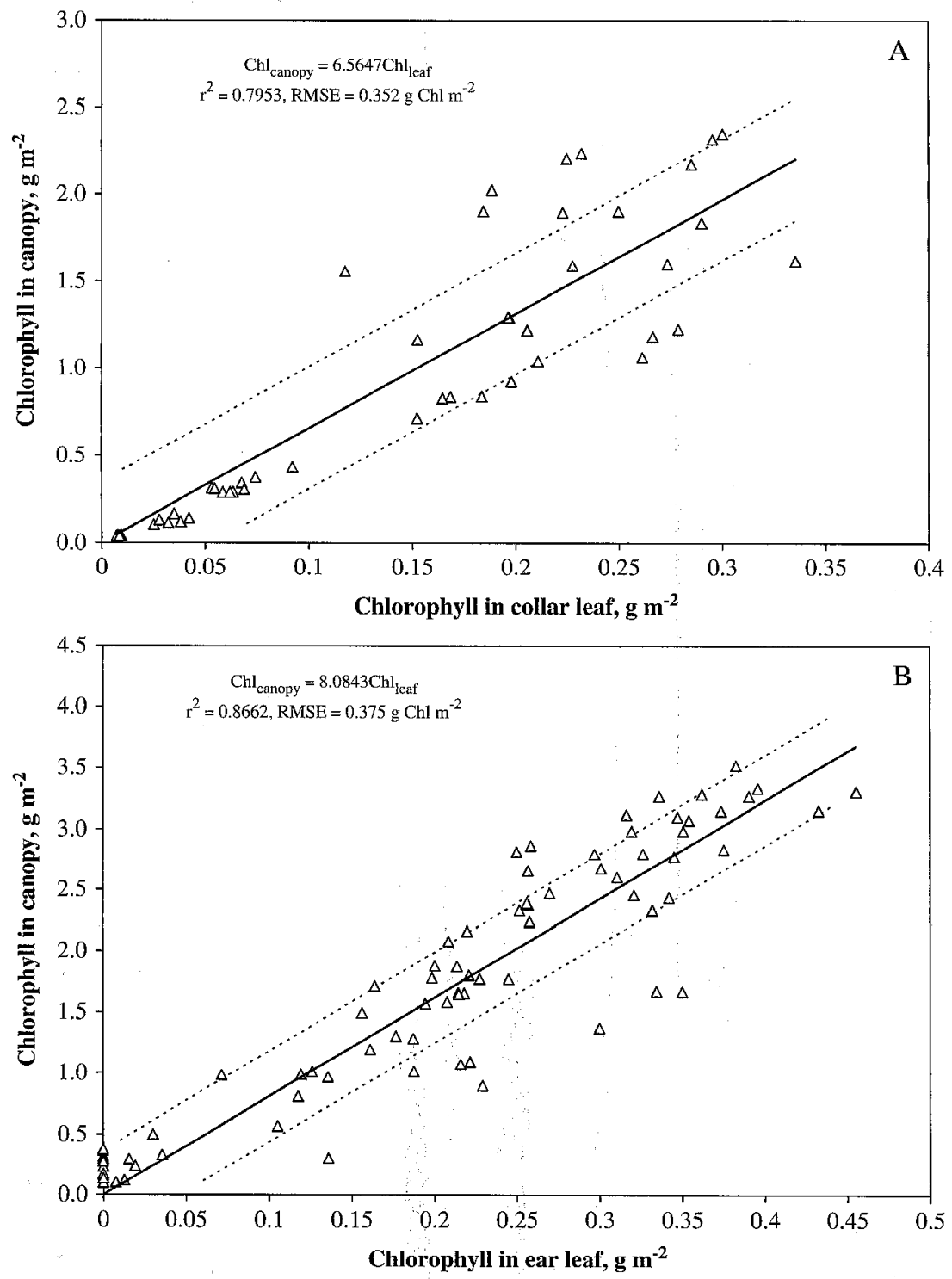

Figure 6. Relationship between chlorophyll content (both calculated per ground area) in (A) the collar leaf and (B) the ear leaf and total chlorophyll content in canopy. The solid line represents the linear fit function; the dotted lines represent one standard error of chlorophyll in canopy estimation. RMSE is root mean-square error of canopy $\mathrm{Chl}$ estimation. 


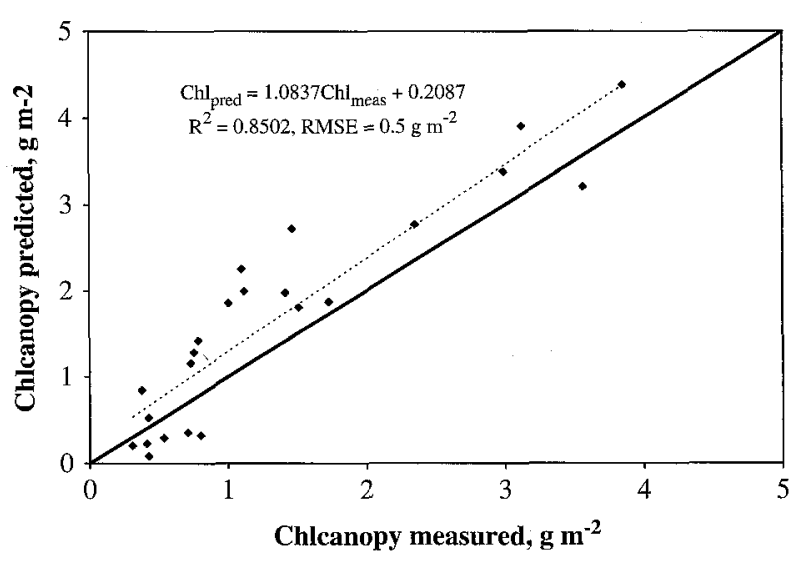

Figure 7. Validation of the model for the estimation of $\mathrm{Chl}$ content in canopy from $\mathrm{Chl}$ content of a single leaf. The measured $\mathrm{Chl}$ content of an independent dataset (2004) was compared with Chl content predicted by Eq. (8) developed with 2005 data. Solid line is $\mathrm{Chl}_{\text {pred }}=\mathrm{Chl}_{\text {meas }}$; dotted line is best-fit function $\mathrm{Chl}_{\text {pred }}$ vs. Chl meas. RMSE is root mean-square error of canopy Chl prediction.

Reproductive period:

$\mathrm{Chl}_{\text {canopy }}=8.08 \times \mathrm{Chl}_{\text {ear }}$

During the vegetative period, $\mathrm{Chl}_{\text {collar }}$ explained around $80 \%$ of the total Chl variability in the canopy (Table 1). During the reproductive period, $\mathrm{Chl}_{\text {ear }}$ explained more than $87 \%$ of $\mathrm{Chl}_{\text {canopy }}$ (Table 1, Figure 6).

For validation of the algorithm for $\mathrm{Chl}_{\text {canopy }}$ retrieval (Eq. (8)), the independent dataset collected during the reproductive period of 2004 was used. The results of the validation are presented in Figure 7. The algorithm predicted Chl content in a canopy with a RMSE of less than $0.5 \mathrm{~g} \mathrm{Chl} \mathrm{m}^{-2}$ for $\mathrm{Chl}_{\text {canopy }}$ that ranged from 0.3 to $4 \mathrm{~g} \mathrm{Chl} \mathrm{m}^{-2}$ :

$\left(\mathrm{Chl}_{\text {canopy }}\right)_{\text {pred }}=1.0837 \times\left(\mathrm{Chl}_{\text {canopy }}\right)_{\text {meas }}+0.2087$

Thus, estimation of canopy Chl per ground area can be done via either the collar or ear leaf $\mathrm{Chl}$ content (per ground area) using the following procedure: (1) measure reflectance in two spectral bands $720-730$ and $770-800 \mathrm{~nm}$; (2) calculate $\mathrm{Cl}_{\text {red }}$ edge: Eq. (1); (3) calculate Chl content of an entire leaf or leaf section: Eq. (5); (4) measure the area of the collar or ear leaf using either portable leaf area meters (e.g., LI-3000C Portable Area Meter http:// www.licor.com/env/Products/AreaMeters/LI-3000C/ 3000C_intro.jsp) or applying the empirical formula developed by Montgomery (1911) and widely used (e.g., Sprague and Curtis, 1933; Muchow and Davis, 1988): individual leaf area $=0.75 \times$ leaf length $\times$ maximal leaf width; (5) calculate Chl weaf leaft: Eq. (3); and (6) calculate Chl canopy: Eqs. (7) or (8).

\section{Estimation of canopy Chl from multiple leaves.}

To establish relationships between $\mathrm{Chl}_{\text {canopy }}$ and $\mathrm{Chl}$ in multiple leaves, the $\mathrm{Chl}$ content of leaves above or below 0 leaf were added successively to Chl content in 0 leaf until the topmost or the lowermost leaf was included. The $r^{2}$ of the relationship $\mathrm{Chl}_{\text {leaves }}$ vs. $\mathrm{Chl}_{\text {canopy }}$ plotted vs. number of leaves added is shown in Figure 8 . The addition of $\mathrm{Chl}$ in leaves positioned below or above the collar leaf to $\mathrm{Chl}_{\text {collar }}$ into the regression analysis had very different effects on the accuracy of $\mathrm{Chl}_{\text {canopy }}$ estimation (Figure 8A). Adding leaves below the collar leaf increased the statistical significance considerably: $r^{2}$ grew from 0.79 to 0.97 up to the point when the -5 leaf was added. Adding additional leaves did not change the relationship. Thus, $\mathrm{Chl}$ in leaves positioned below the collar leaf contributed noticeably to total $\mathrm{Chl}_{\text {canopy }}$ and measuring $\mathrm{Chl}$ in three leaves instead of one collar leaf made a difference in $\mathrm{Chl}_{\text {canopy }}$ estimation: the $r^{2}$ increased from 0.79 to 0.94 .

Just the opposite effect on $\mathrm{Chl}_{\text {canopy }}$ estimation was seen when $\mathrm{Chl}$ in leaves positioned above the collar leaf was added into the analysis. The accuracy of $\mathrm{Chl}_{\text {canopy }}$ estimation decreased after adding only one leaf. It shows that $\mathrm{Chl}$ in leaves positioned above the collar leaf were not repre-

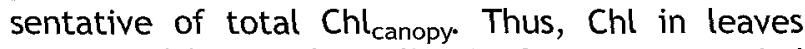
positioned below the collar leaf is recommended for estimation of $\mathrm{Chl}_{\text {canopy. The decision to use more }}$ than one leaf for canopy $\mathrm{Chl}$ estimation should balance the gain in accuracy in the estimation with the extra labor that comes with the estimation of $\mathrm{Chl}$ content of more than just one leaf.

The significance of adding leaves to the regression analysis for the ear leaf (Figure 8B) was conspicuously different than for the collar leaf (Figure 8A). The initial $r^{2}$ for the ear leaf was higher than for the collar leaf ( 0.87 vs. 0.79$)$, but the addition of leaves to the ear leaf analysis was less pronounced than in the case of the collar leaf (Figure 8B). Adding $\mathrm{Chl}$ in leaves above the ear leaf slightly increased $r^{2}$ (opposite that of for the collar leaf). Thus, $\mathrm{Chl}$ in leaves positioned below the ear leaf is recommended to determine canopy $\mathrm{Chl}$ with two to four leaves being optimal. The latter brought an increase in $r^{2}$ from 0.87 to more than 0.95 . 

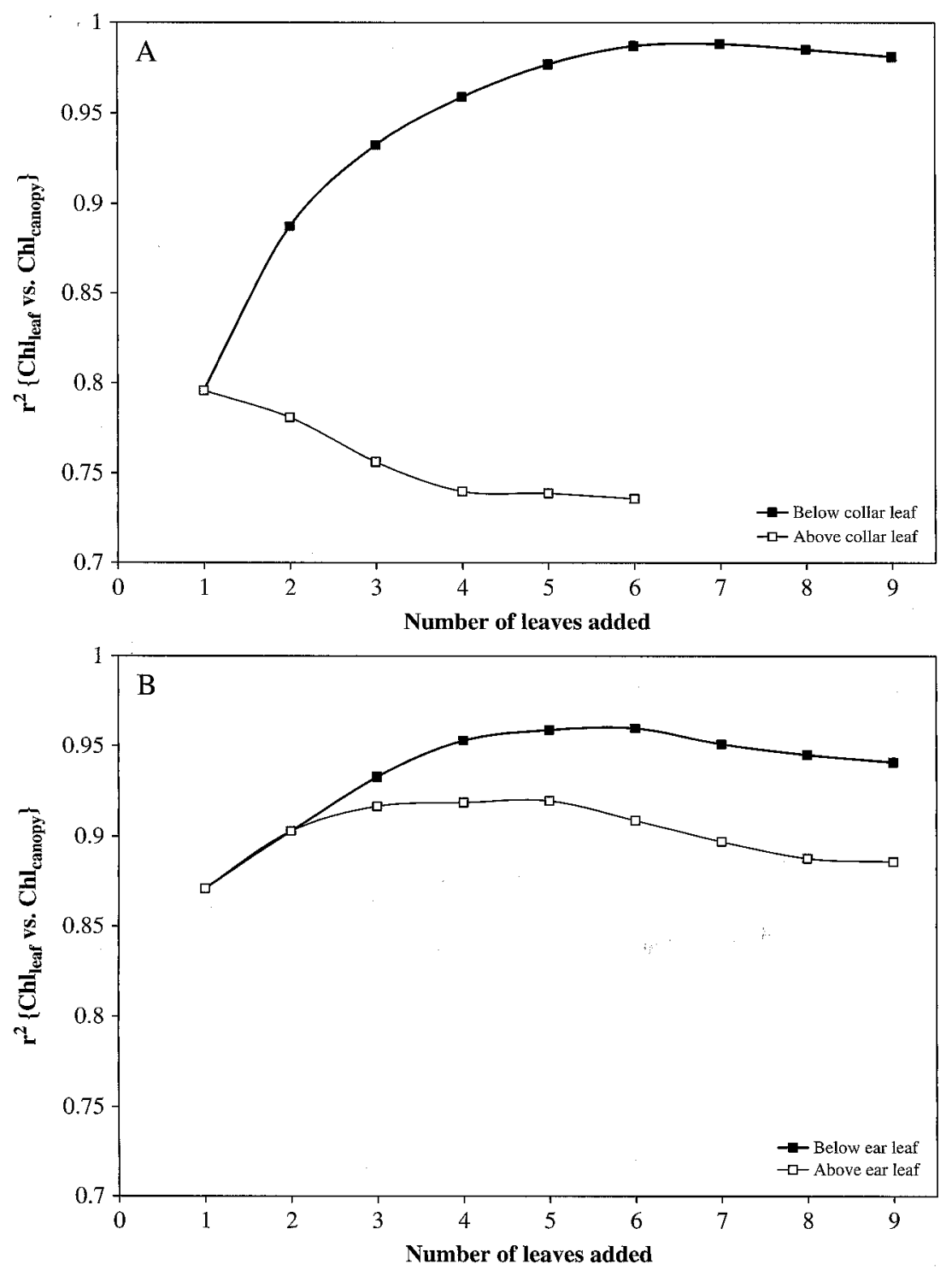

Figure 8. The coefficient of determination, $r^{2}$, of the linear relationship between chlorophyll content in leaves and total chlorophyll in canopy (both calculated per ground area) with successive addition of leaves, either below or above the collar (A) and ear (B) leaf.

\section{References}

Barton CVM. A theoretical analysis of the influence of heterogeneity in chlorophyll distribution on leaf reflectance. Tree Physiol 2000;21:789-95.

Brougham RW. The relationship between the critical leaf area, total chlorophyll content, and maximum growthrate of some pasture and crop plants. Ann Bot 1960;24:463-74.

Buschmann C, Nagel E. In vivo spectroscopy and internal optics of leaves as basis for remote sensing of vegetation. Int J Remote Sens 1993;14: 711-22.

Collins WE. Remote sensing of crop type and maturity. Photogram Eng Remote Sens 1978;44:43-55.

Coops NC, Stone C, Culvenor DS, Chisholm LA, Merton RN. Chlorophyll content in eucalypt vegetation at the leaf and canopy scales as derived from high resolution spectral data. Tree Physiol 2003;23:23-31.

Curran PC, Milton EJ. The relationships between the chlorophyll concentration, LAl and reflectance of a simple vegetation canopy. Int J Remote Sens 1983;4: 247-55.

Curran PJ, Dungan JL, Gholz HL. Exploring the relationship between reflectance red-edge and chlorophyll content in slash pine. Tree Physiol 1990;7:33-48.

Dawson TP, North PRJ, Plummer SE, Curran PJ. Forest ecosystem chlorophyll content: implications for remotely sensed estimates of net primary productivity. Int J Remote Sens 2003;24:611-7.

Evans JR. Photosynthesis and nitrogen relationships in leaves of $C_{3}$ plants. Oecologia 1989;78:9-19.

Foyer CR, Leegood, Walker D. What limits photosynthesis? Nature 1982;298:326. 
Gitelson AA, Merzlyak MN. Spectral reflectance changes associated with autumn senescence of Asculus hippocastanum and Acer platanoides leaves. Spectral features and relation to chlorophyll estimation. J Plant Physiol 1994;143:286-92.

Gitelson AA, Merzlyak MN. Signature analysis of leaf reflectance spectra: algorithm development for remote sensing of chlorophyll. J Plant Physiol 1996;148:494-500.

Gitelson AA, Gritz U, Merzlyak MN. Relationships between leaf chlorophyll content and spectral reflectance and algorithms for non-destructive chlorophyll assessment in higher plant leaves. J Plant Physiol 2003;160:271-82.

Gitelson AA, Viña A, Rundquist DC, Ciganda V, Arkebauer TJ. Remote estimation of canopy chlorophyll content in crops. Geophys Res Lett 2005;32:L08403.

Gitelson AA, Viña A, Verma SB, Rundquist DC, Arkebauer TJ, Keydan G, et al. Relationship between gross primary production and chlorophyll content in crops: implications for the synoptic monitoring of vegetation productivity. J Geophys Res 2006a;111:D08S11.

Gitelson AA, Keydan GP, Merzlyak MN. Three-band model for noninvasive estimation of chlorophyll, carotenoids, and anthocyanin contents in higher plant leaves. Geophys Res Lett 2006b;33:L11402.

Hu B, Qian SE, Haboudane D, Miller JR, Hollinger AB, Tremblay N, et al. Retrieval of crop chlorophyll content and leaf area index from decompressed hyperspectral data: the effects of data compression. Remote Sens Environ 2004;92:139-52.

Kull O. Acclimation of photosynthesis in canopies: models and limitations. Oecologia 2002;133:267-79.

Le Maire G, Francois C, Dufrene E. Towards universal broad leaf chlorophyll indices using PROSPECT simulated database and hyperspectral reflectance measurements. Remote Sens Environ 2004;89:1-28.

Lieth $\mathrm{H}$, Whittaker $\mathrm{RH}$. Primary production of the biosphere. New York: Springer-Verlag; 1975. 339pp.

Markwell J, Osterman JC, Mitchell JL. Calibration of the Minolta SPAD-502 leaf chlorophyll meter. Photosynth Res 1995;46:467-72.

Montgomery EG. Correlation studies in corn. 24th Annual Report, Agricultural Experiment Station of Nebraska; 1911. p. 109-59.
Muchow RC, Davis R. Effect of nitrogen supply on the comparative productivity of maize and sorghum in a semi-arid tropical environment. II Radiation interception and biomass accumulation. Field Crops Res 1988; 18:17-30.

Piekielek WP, Fox RH. Use of a chlorophyll meter to predict sidedress nitrogen requirements for maize. Agron J 1992;84:59-65.

Porra RJ, Thompson WA, Kriedemann PE. Determination of accurate extinction coefficients and simultaneous equations for assaying chlorophylls $a$ and $b$ extracted with four different solvents: verification of the chlorophyll standards by atomic absorption spectroscopy. Biochim Biophys Acta 1989;975: 384-94.

Richardson $A D$, Duigan SP, Berlyn GP. An evaluation of noninvasive methods to estimate foliar chlorophyll content. New Phytol 2002;153:185-94.

Ritchie SW, Hanway JJ, Benson GO. How a corn plant develops. Special Report \#48. Ames, IA: lowa State University of Science and Technology. Cooperative Extension Service; 1992.

Sims DA, Gamon JA. Relationship between leaf pigment content and spectral reflectance across a wide range species, leaf structures and development stages. Remote Sens Environ 2002;81:337-54.

Sprague HB, Curtis N. Chlorophyll content as an index of the productive capacity of selfed lines of corn and their hybrids. Agron J 1933;25:709-24.

Steele M, Gitelson AA, Rundquist DC. A comparison of two techniques for non-destructive measurement of chlorophyll content in grapevine leaves. Agron J 2008;100: 779-82.

Tucker CJ. Asymptotic nature of grass canopy spectral reflectance. Appl Opt 1977;16:1151-6.

Viña A, Gitelson AA. New developments in the remote estimation of the fraction of absorbed photosynthetically active radiation in crops. Geophys Res Lett 2005; 32:L17403.

Walters DT. Diagnosis of nitrogen deficiency in maize and the influence of hybrid and plant density. In: North central extension-industry soil fertility conference, vol. 19, Des Moines, IA. 2003. 